\title{
Préstamos del español en el Diccionario Quechua Junín-Huanca ${ }^{1}$
}

\author{
Loanwords from Spanish in a Junin-Huanca Quechua Dictionary
}

Marco Aurelio Ferrell Ramírez ${ }^{2}$

\section{RESUMEN}

Cuando dos lenguas entran en contacto, invariablemente se produce una interacción en la cual una lengua recibe influencias de la otra, como elementos del léxico y fonética.

En el caso del quechua huanca (del dpto. de Junín), el diccionario bilingüe de Rodolfo CerrónPalomino (Diccionario Quechua Junín-Huanca) presenta una amplia muestra de la huella del español en el quechua y de cómo el quechua adapta las palabras que toma del castellano. Así, la vocal acentuada del español puede interpretarse con vocal larga en quechua (lado > laadu), la [o] del español puede representarse con una vocal cerrada [u] (gallo $>$ gaallu), los diptongos pueden simplificarse (antiguo > antiibu, apuesta $>$ apusti), las consonantes pueden cambiar (horqueta $>$ hurhita, suegra $>$ suydra), etc.

\section{Palabras clave}

Quechua, español, préstamo lingüístico, fonología.

\begin{abstract}
When two languages come in contact, an interplay invariably takes place in which one language receives influences from the other, both lexical and phonological.

Rodolfo Cerrón's bilingual dictionary (Diccionario Quechua Junín-Huanca) is a relevant example, as it presents a wide range of samples of Spanish words adapted to the Quechua phonological patterns. So, a Spanish stressed vowel can be interpreted as a long vowel (lado > laadu), Spanish $[\mathrm{O}]$ is interpreted as a close vowel [u] (gallo > gaallu), Spanish dipthongs can be simplified (antiguo $>$ antiibu, apuesta $>$ apusti), Spanish consonants can be changed (horqueta $>$ hurhita, suegra $>$ suydra), etc.
\end{abstract}

\section{Keywords}

Quechua, Spanish, linguistic loan, phonology.

\section{Introducción}

En esta ocasión analizamos el Diccionario Quechua Junín-Huanca, de Rodolfo CerrónPalomino, que el Ministerio de Educación y el Instituto de Estudios Peruanos publicaron en 1976 como parte de una colección de seis gramáticas y diccionarios correspondientes a las variedades Cuzco-Collao, AyacuchoChanca, Junín-Huanca. Áncash-Huailas, Cajamarca-Cañaris y San Martín.

El estudio gramatical y lexicográfico de las lenguas nativas del Perú necesariamente toma en cuenta la interrelación entre dichas lenguas y la dominante y de prestigio cultural, que es el castellano.

Conferencia de 3 de octubre de 2013 en Coloquio de Lexicografía en la UNMSM.

Excatedrático de la Universidad Nacional de Educación. Investigador en lenguas andinas, con artículos publicados. Autor del libro Manual de uso idiomático. Corrector de textos de amplia experiencia. 
En una situación de contacto de lenguas, los aportes de una a otra ocurren en los aspectos fonológicos, gramaticales y léxicos. Pasamos revista a los aspectos principales de la presencia del castellano en el vocabulario del quechua huanca recogido por Cerrón-Palomino.

\section{Aspecto fonológico}

Las palabras del léxico del quechua huanca que tienen procedencia castellana experimentan una adaptación que las asimila a las características fonológicas de la lengua. En este sentido, podemos señalar lo siguiente.

\subsection{Vocales}

Las palabras que vienen del castellano, lengua que tiene cinco vocales con valor fonológico, se ajustan al patrón de tres vocales ${ }^{3}$ que tiene la lengua receptora, lo que coincide con préstamos en otras variedades del quechua.

Para interpretar las adaptaciones de los préstamos, es necesario tener en cuenta que en el quechua huanca la cantidad vocálica tiene implicancias morfofonológicas; por ejemplo, el sufijo de acusativo -kta pierde su primera consonante si se aplica a palabra terminada en consonante o vocal larga. Ejemplos:

Las vocales medias /e/, /o/ del español se realizan como vocales altas:

$\begin{aligned} \text { asadun } & <\text { azadón } \\ \text { bayita } & <\text { bayeta } \\ \text { birdi } & <\text { verde } \\ \text { dihay } & <\text { ideja! (interj. De los gañanes) } \\ \text { istaka } & <\text { estaca } \\ \text { kaldiya } & <\text { caldear } \\ \text { pulbu } & <\text { polvo } \\ \text { tabardillu } & <\text { tabardillo }\end{aligned}$

\subsection{Diptongos}

Cuando la palabra tomada en préstamo tiene diptongo, se reinterpreta dándole forma de un diptongo propio del quechua, se simplifica o se reemplaza con vocal larga (un caso). Pero hay un ejemplo de diptongo castellano con /w/ que al pasar al quechua no se conforma a la norma de esa lengua, como cuatro, duende o suerte, que han pasado al quechua creando un haz consonántico que no es original en quechua.

Pérdida de un elemento del diptongo

$\begin{array}{ll}\text { antiibu } & <\text { antiguo } \\ \text { apusti } & <\text { apuesta } \\ \text { disimri } & <\text { diciembre } \\ \text { mirinda } & <\text { merienda }\end{array}$

Modificación del diptongo

$\begin{array}{ll}\text { fuyti } & <\text { foete } \\ \text { huybis } & <\text { jueves } \\ \text { ruyduy } & <\text { ruido } \\ \text { pañuylu } & <\text { pañuelo } \\ \text { siilu } & <\text { cielo } \\ \text { suydra } & <\text { suegra }\end{array}$

Relativa conservación del diptongo

chikurya $<$ achicoria

hunyu $<$ junio

iiwa $<$ yegua

lasyay $<$ lacear

lasyadiira $<$ laceadera

midyas $<$ media(s)

sawmay $<$ sahumar

tayta $<$ taita

Diptongo con $/ w /$ precedida por consonante

kwatru $<$ cuatro

kwintu $<$ cuento

swirti $<$ suerte

twintuy $<$ duende

\subsection{Acento}

Todas las palabras que vienen del castellano sean agudas, graves o esdrújulas - se utilizan en quechua huanca con acento grave, y hay en esto una tendencia a realizar con vocal larga la sílaba que en español tiene el acento. Sin embargo, cuando el préstamo (por ej., muuday) recibe un sufijo y corre el acento, se

Los estudios lingüísticos (cf. Cerrón-Palomino 1987, Napurí 2013, Pérez 2016) establecen con seguridad que el quechua tiene tres vocales con valor fonológico (provocan cambio en el significado de la palabra): /a/, /i/, /u/. En quechua las realizaciones vocálicas $[e]$ y $[0]$ no son fonemas sino fonos, esto es, simplemente son variantes que se explican por: a) condicionamiento de consonante postvelar /q/; b) préstamo de otra lengua; c) simplificación de diptongos, por ejemplo ay $>e$, aw $>0$. 
conserva la vocal larga: muudana (acentuada en -da-). La palabra músico pasa al quechua con una vocal larga que refleja la acentuación esdrújula original, pero en quechua el acento es grave: músico > muusiku (con acento en la segunda sílaba, -si-).

Todas son palabras graves

$\begin{array}{ll}\text { abaanu } & <\text { habano (color canela) } \\ \text { amiigu } & <\text { amigo } \\ \text { aanimu } & <\text { ánimo } \\ \text { buutas } & <\text { botas } \\ \text { gallariita } & <\text { gallareta } \\ \text { laaha } & <\text { laja } \\ \text { llaanu } & <\text { llano } \\ \text { muday } & <\text { mudar (de ropa) } \\ \text { muudana } & <\text { muda 'ropa de cambio', 'muda' } \\ \text { muusu } & <\text { mozo } \\ \text { raatu } & <\text { rato }\end{array}$

\subsection{Consonantes}

Los préstamos con consonantes oclusivas sonoras (/b/, /d/, /g/) han influido en incorporar al sistema fonológico del quechua huanca estas entidades no presentes en el repertorio patrimonial. En el diccionario se ve con claridad que las palabras que tienen estas consonantes son procedentes del español, con pocas excepciones (como agushka, chimbay y kundur, los dos últimos quechuismos prestados del español regional).

En un caso, la consonante oclusiva velar $/ \mathrm{k} /$ del español se asimiló con espirantización y aspiración (horqueta $>$ hurhita). Por otro lado, ninguna palabra de préstamo con la africada palatal /ch/ se ha asimilado con la africada palatal retrofleja /tr/ del huanca. Esto no es obvio, pues en aimara y jacaru tenemos ejemplos de consonantes "simples" del español que no han sido asimiladas con sus semejantes propias "simples" (sin rasgo coarticulatorio); así, azotar y coche ("chancho") dieron en aimara asut'iña (no asutiña) y khuchi (no kuchi); de hacha resultó en jacaru jach'a (no jacha).

En algunos casos, la consonante oclusiva sonora se ha interpretado con sonidos de la lengua, como en aawash, alwish, kawallu; pero a veces sonoriza la consonante oclusiva:

kulandru, kumbindu, yunda.

Oclusivas sonoras /b/, /d/, /g/ conservadas

$$
\begin{array}{ll}
\text { balur } & <\text { valor } \\
\text { balurchay } & <\text { valor ("infundirse de valor") } \\
\text { daañu } & <\text { daño } \\
\text { diyus } & <\text { dios } \\
\text { fayna } & <\text { faena } \\
\text { gaallu } & <\text { gallo } \\
\text { ingañay } & <\text { engañar } \\
\text { laadu } & <\text { lado } \\
\text { Saabadu } & <\text { sábado } \\
\text { tuldiira } & <\text { toldera }
\end{array}
$$

Consonantes oclusivas sonoras $/ d /, / g /$ se modifican

$\begin{array}{ll}\text { antiibu } & <\text { antiguo } \\ \text { siniya } & <\text { ciénaga } \\ \text { suydra } & <\text { suegra }\end{array}$

Conversión de oclusiva sonara $/ b />/ w /$

kawallu $<$ caballo

aawash $<$ haba(s)

alwish $<$ arveja

wispira $<$ víspera

Consonante oclusiva velar espirantizada

hurhita $<$ horqueta (herramienta agrícola) warraahu $<$ verraco

Sonorización de oclusiva sorda $\mid t />/ d /$ en contacto con $/ \mathrm{n} /$

kulandru $<$ culantro

kumbindu $<$ convento

yunda $<$ yunta

\section{Léxico}

Si bien la introducción de préstamos responde a la necesidad de tener palabras para nuevos objetos o referentes que no existen en la lengua receptora, los significados de las palabras procedentes del castellano no siempre tienen el significado que conocemos.

Corresponden en significado

alfa < alfalfa

ardiidi $<$ adrede 


$\begin{array}{ll}\text { fuyti } & <\text { foete } \\ \text { giisu } & <\text { guiso } \\ \text { iilu } & <\text { hilo } \\ \text { kasaray } & <\text { casarse } \\ \text { kuusha } & <\text { hoz } \\ \text { laasu } & <\text { lazo } \\ \text { maachurra } & <\text { machorra } \\ \text { mirkulis } & <\text { miércoles } \\ \text { nuwillu } & <\text { novillo } \\ \text { raama } & <\text { rama } \\ \text { siñalaay } & <\text { señalar } \\ \text { tirsu } & <\text { tercio } \\ \text { tuuru } & <\text { toro } \\ \text { uuru } & <\text { oro } \\ \text { warraahu } & <\text { verraco } \\ \text { waaka } & <\text { vaca }\end{array}$

Hay variación de significado

daañu < daño ("sembrío maltratado por los animales")

gandiidu $<$ bandido

("interesado", "famélico")

ilibaadu < elevado

("alterado espiritualmente")

kartay < cartear ("escribir, comunicarse a través de correspondencia")

piisay < piezar ("agregar un retazo de tela a vestido o a telar")

punta < punta ("comienzo", "principio")

raatu < rato ("rápidamente")

No son de origen castellano

ipu < esp. reg. hipo ("espina menuda de la tuna")

maanu < mano ("acreedor; persona que debe")
La primera, "ipu", es una realización en que ha caído la postvelar inicial (qipu > ipu), fenómeno frecuente en quechua huanca. Esta palabra es común del quechua y del aimara. El diccionario de quechua Cuzco-Collao trae "QEPO. s. espinilla de la tuna o de los cactus". La segunda, "manu", es también compartida por el quechua y el aimara, y está en los diccionarios de Bertonio y de Gonçález Holguín.

\section{Morfología}

Los elementos nominales y verbales forman con sufijos quechuas muchas palabras con apariencia quechua.

\begin{tabular}{|c|c|}
\hline alwish & $<$ arveja \\
\hline & < arte ("engañar") \\
\hline & $\begin{array}{l}<\text { arar ("aporcar la papa con una } \\
\text { yunta") }\end{array}$ \\
\hline aawash & $<$ haba(s) \\
\hline balurchay & $\begin{array}{l}<\text { valor ("infundirse de valor", } \\
\text { "darse ánimos") }\end{array}$ \\
\hline dibuhay & $<$ dibujar \\
\hline kasarakuy & $\begin{array}{l}<\text { casar(se) ("casamiento", } \\
\text { "matrimonio") }\end{array}$ \\
\hline xuulis & $<\operatorname{col}(e s)$ \\
\hline piyurtaay & $\begin{array}{l}<\text { peor ("empeorar } \\
\text { enfermedad") }\end{array}$ \\
\hline ruydupaay & < ruido ("reñir, buscar líos") \\
\hline silgish & $<$ silguero \\
\hline sindikuy & $\begin{array}{c}<\text { encender ("velar a imagen o a } \\
\text { difunto colocando velas") }\end{array}$ \\
\hline intichay & $\begin{array}{c}<\text { cinta ("poner cintas a las orejas } \\
\text { de los animales") }\end{array}$ \\
\hline & $<$ oveja < ovexa \\
\hline
\end{tabular}




\section{REFERENCIAS}

Academia Española de la Lengua (2001) Diccionario de la Lengua Española, Madrid, EspasaCalpe S. A., 22. ${ }^{\text {a edición. }}$

Bertonio, Ludovico (1984 [1612]) Vocabvlario de la Lengva Aymara, Cochabamba. Ed. facsimilar de CERES, IFEA, MUSEF.

Büttner, Thomas y Condori, Dionisio (1984) Diccionario Aymara-Castellano Arunakan Liwru Aymara Kastillanu, Lima-Puno.

Cerrón-Palomino, Rodolfo (1976a) Diccionario quechua Junín-Huanca, Lima, Instituto de Estudios Peruanos y Ministerio de Educación.

Cerrón-Palomino, Rodolfo (1976b) Gramática quechua Junín-Huanca, Lima, Instituto de Estudios Peruanos y Ministerio de Educación.

Cerrón-Palomino, Rodolfo (1987) Lingüistica quechua, Cuzco, Centro de Estudios Regionales Andinos Bartolomé de las Casas.

Cusihuamán, Antonio (1976) Diccionario quechua Cuzco-Collao, Lima, Instituto de Estudios Peruanos y Ministerio de Educación.

Gonçález Holguín, Diego (1989 [1608]) Vocabvlario de la Lengva General de todo el Perv, Lima, UNMSM. Edición publicada con auspicio de Concytec, basada en la del Instituto Nacional de Historia (1952).

Lira, Jorge A. (1982) Diccionario Kkechuwa-Español, Bogotá, 2. a edición, Secretaría Ejecutiva Permanente del Convenio "Andrés Bello".

Lira, Jorge A. y Mejía Huamán, Mario (2004) Diccionario Quechua-Castellano CastellanoQuechua, Lima, Universidad Ricardo Palma.

Lucca, Manuel de (1987) Diccionario Práctico Aymara-Castellano Castellano-Aymara, La PazCochabamba, Los Amigos del Libro.

Napurí, Andrés (2013) "Adquisición de las vocales anteriores del español por hablantes de quechua" en Estudios interlingüísticos, N. ${ }^{\circ}$ 1, Asociación de Jóvenes Lingüistas, pp. 87-101.

Palmer, Leonard 1975 Introducción critica a la lingüística descriptiva y comparada, Madrid, Gredos.

Parker, Gary (1976) Gramática quechua Áncash-Huailas, Lima, Instituto de Estudios Peruanos y Ministerio de Educación.

Parker, Gary y Chávez, Amancio (1976) Diccionario quechua Áncash-Huailas, Lima, Instituto de Estudios Peruanos y Ministerio de Educación. 
Pérez, Jorge Iván (2016) "La representación de los procesos fonológicos: a propósito de descenso ocálico del quechua" en Revista del Instituto Riva-Agüero, vol. 1, N. ${ }^{\circ}$ 1, Lima, mayo, Instituto Riva-Agüero, pp. 61-100.

Taylor, Gerald (1999 [1610]) Ritos y tradiciones de Huarochirí, Lima, Instituto Francés de Estudios Andinos (IFEA), Banco Central de Reserva y Universidad Particular Ricardo Palma, 2. a edición.

Torero, Alfredo (2002) Idiomas de los Andes Lingüística e historia, Lima, IFEA y Horizonte.

Fecha de recepción: 15-08-16

Fecha de aceptación: 10-11-16 